\title{
Anticancer effect of ursolic acid via mitochondria-dependent pathways (Review)
}

\author{
XUE-MIN FENG and XIU-LAN SU \\ Clinical Medical Research Center of The Affiliated Hospital, \\ Inner Mongolia Medical University, Hohhot, Inner Mongolia 010050, P.R. China
}

Received July 27, 2018; Accepted February 1, 2019

DOI: $10.3892 / \mathrm{ol} .2019 .10171$

\begin{abstract}
Ursolic acid is a plant-derived pentacyclic triterpenoid found in various medicinal herbs and fruits. It has generated clinical interest due to its anti-inflammatory, antioxidative, antiapoptotic and anticarcinogenic effects. An increasing amount of evidence supports the anticancer effect of ursolic acid in various cancer cells. One of the hallmarks of malignant transformation is metabolic reprogramming that sustains macromolecule synthesis, bioenergetic demand and tumor cell survival. Mitochondria are important regulators of tumorigenes is as well as a major site of the metabolic reactions that facilitate this reprogramming and adaption to cellular and environmental changes. The current review explored the close association between the anticancer effect of ursolic acid and the activation of mitochondrial-dependent signaling pathways.
\end{abstract}

\section{Contents}

1. Introduction

2. Structure and function of ursolic acid

3. Anticancer effect of ursolic acid via mitochondrial energy metabolism

4. Anticancer effect of ursolic acid via reduction of mitochondrial oxidative stress

5. Anticancer effect of ursolic acid mediated by the p53-modulated mitochondrial pathway

6. Conclusions and perspectives

\section{Introduction}

Aerobic glycolysis in cancer cells, also referred to as the 'Warburg effect', was first observed and described by Warburg

Correspondence to: Professor Xiu-Lan Su, Clinical Medical Research Center of The Affiliated Hospital, Inner Mongolia Medical University, 1 Tong Dao North Road, Hohhot, Inner Mongolia 010050, P.R. China E-mail: xlsu@hotmail.com

Key words: ursolic acid, cancer, mitochondrial, review
90 years ago $(1,2)$. The Warburg effect suggests that tumor cells produce excessive amount of lactate in the presence of oxygen (3). This effect has been studied extensively improving the understanding of various metabolic characteristics of tumor cells (4-6). Elucidating the mechanisms underlying the expression levels and/or activity of key catalytic enzymes involved in tumor cell metabolic pathways may improve cancer diagnosis and treatment.

Normal cells can metabolize glucose to produce pyruvate by the process of glycolysis, which occurs in the cytoplasm. The tricarboxylic acid cycle oxidizes the majority of glycolysis substrates into pyruvate and carbon dioxide. Oxygen and the mitochondrial electron transport chain are required to generate an electrochemical gradient and facilitate adenosine triphosphate (ATP) production (7). The metabolic abnormalities of tumor cells are manifested when aerobic glycolysis is severely altered (6). The tumor-associated changes in glycolysis include weakened oxidative phosphorylation, accelerated pentose phosphate metabolic pathway, activated glutamine catabolism, fatty acid de novo synthesis and $\beta$-oxidations (8). In order to meet the increased demand of tumor cells for energy and substance anabolism, metabolic reprogramming redefines and directs the flow and flux of nutrients to the metabolic network of tumor cells (3). Much of this reprogramming depends on mitochondria as functional biosynthetic organelles. The metabolic signatures of cancer cells are not restricted to passive responses to damaged mitochondria, but result from oncogene-directed metabolic reprogramming, which is required for support of anabolic growth (8).

Current cancer research focuses on targeting cancerassociated defects in apoptosis. Mitochondria are not only the major center of cell respiration and oxidative phosphorylation, but also the control center of apoptosis. Apoptosis is regulated by two major mechanisms. The extrinsic pathway, or death-receptor pathway, is mediated by the transduction of extracellular death receptor ligand signaling (9). The intrinsic pathway, also referred to as the mitochondrial pathway, is governed by a specific mitochondrion-localized signaling cascade. The activation of the mitochondrial death pathway includes changes in mitochondrial outer membrane permeabilization, membrane potential $(\Delta \Psi \mathrm{m})$ collapse, assembly of the permeability pore complex and the activation of pro-apoptotic B-cell lymphoma 2 (Bcl-2) family members apoptotic regulator BAX (Bax) and Bcl-2 homologous antagonist/killer (10). 
The anti-apoptotic Bcl-2 family members, including Bcl-2 and B-cell lymphoma-extra large, mediate signaling in normal physiology to prevent cell death (11). Pro-apoptotic proteins oligomerize at the outer membrane of the mitochondria to mediate mitochondrial outer membrane permeabilization that works in tandem with the voltage dependent anion channel (VDAC) and adenine nucleus translocator (ANT) protein (10). This complex activation of different target proteins results in pore formation and the release of cytochrome $\mathrm{C}$ from mitochondria into the cytosol (12). Cytochrome $\mathrm{C}$ activates caspases, the executors of programmed cell death which trigger a caspase cascade reaction cleaving $>100$ substrates in cells and leading to cell apoptosis $(12,13)$.

Selective targeting of cancer metabolism and apoptosis-associated signaling may provide an alternative strategy for the development of anticancer drugs that have minimal adverse effects on normal cells. The current review focuses on the role of ursolic acid (UA) as a potential anticancer drug that influences mitochondrial function.

\section{Structure and function of ursolic acid}

UA is a pentacyclic triterpenoid (14). UA-associated compounds include oleanolic acid, betulinic acid, uvaol and $\alpha$ - and $\beta$-amyrin (14). Triterpenoids have been used as ingredients of herb extracts employed in traditional medicine. The presence of UA has been confirmed in numerous classes of medicinal plants including the peels of the orchard apple (Malus domestica), marjoram (Origanum majorana) leaves, oregano (Origanum vulgare) leaves, rosemary (Rosmarinus officinalis) leaves, sage (Salvia officinalis) leaves, thyme (Thymus vulgaris) leaves, lavender (Lavandula angustifolia) leaves and flowers, eucalyptus (Eucalyptus) leaves and bark, black elder (Sambucus nigra) leaves and bark, hawthorn (Crataegus spp.) leaves and flowers, coffee (Coffea arabica) leaves as well as the wax layer of numerous edible fruits (15-17). The chemical structure of UA (3 3 -hydroxy-urs-12-en-28-oic-acid) is presented in Fig. 1. UA has the molecular formula $\mathrm{C}_{30} \mathrm{H}_{48} \mathrm{O}_{3}$, a molecular weight of $456.70032 \mathrm{~g} / \mathrm{mol}$ and a melting point of $283-285^{\circ} \mathrm{C}$. UA can be dissolved in methanol, pyridine and acetone, but is insoluble in water and petroleum ether (18).

UA and its derivatives exhibit potent biological and pharmaceutical effects (18). The anti-inflammatory effect of UA was linked to attenuation of production of proinflammatory cytokines including tumor necrosis factor $\alpha$, interleukin (IL)- 6 and/or IL-17 (19,20). UA was associated with suppression of the nuclear factor- $\kappa \mathrm{B}(\mathrm{NF}-\kappa \beta)$ pathway, inhibition of expression of cyclooxygenase-2 (COX-2) and nitric oxide synthase and the reduction of perhydrides including nitric oxide and hydrogen peroxide (21). Furthermore, UA demonstrated an antidiabetic function and inhibited the activity of pancreatic $\alpha$-amylase, succinate dehydrogenas, and glucose-6-phosphatase and aldose reductase (22). UA also induced fatty acid synthetase activity and glucokinase activity, and upregulated glucose transporter (GLUT) 2 mRNA levels, thereby reducing the blood glucose levels of diabetic mice (22-25).

UA stimulated an increase in the level of plasma total cholesterol, low-density lipoprotein cholesterol, very low-density lipoprotein cholesterol, free fatty acids and phospholipids in high fat diet-fed mice or rabbits (26). By

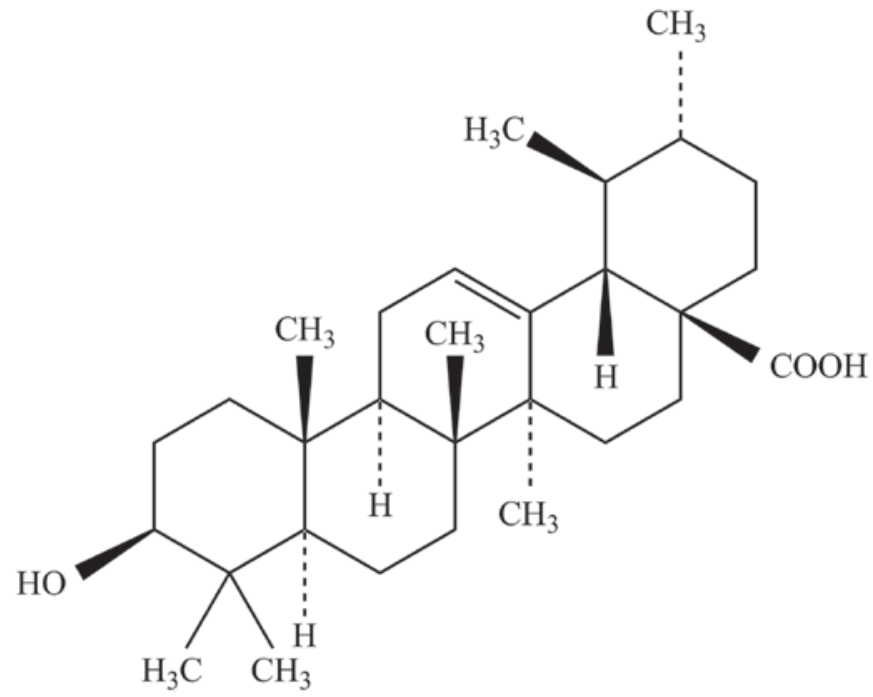

Figure 1. Structure of ursolic acid.

contrast, UA reduced the expression of sterol regulatory element binding protein 1c, Fas cell surface death receptor, acetyl-coenzyme A carboxylase and carnitine palmitoyltransferase-1 (27). UA induced the phosphorylation of adenosine 5'-monophosphate (AMP)-activated protein kinase (AMPK) and stimulated expression of sirtuin 1, thus serving an antihyperlipidemic role (26). UA can provide hepatoprotective activity against several liver diseases, including fatty liver, liver fibrosis, hepatocellular carcinoma and other types of liver cancer by influencing multiple metabolic factors (28). For instance, UA reduced the serum/plasma levels of alanine transaminase and aspartate transaminase, which are liver disease biomarkers $(27,29,30)$.

Numerous studies in rodents and humans have investigated the beneficial effects of UA that targeted cancer cell metabolism. Data demonstrated that UA inhibited tumorigenesis and cancer cell proliferation, modulated apoptosis and cell cycle progression and promoted autophagy (18,31-36). Luo et al (37) reported that treatment with UA inhibited the viability and migration of T47D, MCF-7 and MDA-MB-231 breast cancer cells by targeting phosphoinositide-3-kinase/protein kinase $\mathrm{B}$ (PI3K/Akt)-regulated glycogen synthase kinase $3 \beta$ phosphorylation levels and caspase- 3 activation via the $N F-\kappa \beta$ signaling pathway. Lewinska et al (38) analyzed the effects of low doses of UA in breast cancer cell lines with different hormone and growth factor receptor status. The authors revealed that UA promoted autophagy, apoptosis and induced gap (G)0/G1 cell cycle arrest. Additionally, UA affected glycolysis. The effect was accompanied by decreased levels of ATP, lactate, hexokinase 2 and pyruvate kinase. It was suggested that these effects were mediated by Akt-5'-AMP-activated protein kinase signals, activation of phospho-extracellular signal-regulated kinases1/2 and/or by the oxidative stress pathway. Yeh et al (39) revealed that UA suppressed the migration and metastasis of the MDA-MB-231 breast cancer cell line by modulating c-Jun N-terminal kinase (JNK), Akt and mechanistic target of rapamycin mTOR signaling. UA may down-regulate the expression of COX-2 $(40,41)$. The effect has been observed in various types of cancer cells and was directly proportional to 
tumor aggressiveness and metastasis in gastric cancer SGC7901 cells (34) and hepatic cancer HepG2 cells (42). UA upregulated COX-2 in colorectal cancer HT-29 and prostate cancer DU145 cells (43). Furthermore, it was reported that treatment with UA suppressed the metastasis of HeLa cells, fibrosarcoma HT1080 cells and C6 glioma cells through the downregulation of matrix metallopeptidase $9(33,36,44)$. Furthermore, it has been indicated that UA induced pro-apoptotic signaling in human liver cancer cell lines as well as gastric cancer cell lines, including HepG2, Hep3B, Huh7, AGS, BGC823 and SGC7901 (39,45-48). UA significantly enhanced proapoptotic effects and stimulated mitochondrial dysfunction by activating caspases 3, 8 and 9, and downregulated Bcl-2 expression in these cancer cells.

\section{Anticancer effect of ursolic acid via mitochondrial energy metabolism}

Mitochondria are involved in oxidative phosphorylation and ATP formation in cells; furthermore, $95 \%$ of the energy required for cellular activity is generated in these organelles (49). The regulation of mitochondrial metabolism is associated with the activities of key enzymes in different energy-linked metabolic pathways (50).

Hexokinases (HKs) are irreversible, rate-limiting enzymes in the first step of glycolysis (7). HKs catalyze the conversion of glucose to glucose-6-phosphate with concomitant dephosphorylation of ATP $(8,51)$. Among the four known $\mathrm{HK}$ isoforms, HK2 has the greatest association with tumors (52). It is strategically located on the mitochondrial outer membrane, interacts with the VDAC and provides preferential access to the mitochondrial ATP via ANT in the mitochondrial inner membrane $(53,54)$. This interaction results in a shift in the susceptibility of mitochondria to proapoptotic signals that are mediated through Bcl-2-family proteins. The upregulation, or increased activity of $\mathrm{HK}$ accelerate glycolysis in tumor cells and increase their energy metabolism. The enhancement of glycolysis increases the production of lactate, which acidifies the tumor microenvironment (53). The acidified extracellular fluid decomposes and destroys the cell matrix, thus facilitating the invasion of tumor cells into surrounding tissues (8).

Several studies indicated that UA may modulate the expression and function of mitochondria-associated enzymes, resulting in antiproliferative and apoptosis-promoting effects in various experimental cancer models in vitro and in vivo (55-59). Lewinska et al (38) demonstrated that UA downregulated the Akt signaling in three breast cancer cell lines with different phenotypes including MCF-7 estrogen receptor (ER) positive; progesterone receptor (PR) positive or negative; human epidermal growth factor receptor 2 (HER2) negative, MDA-MB-231 (ER negative; PR negative; HER2 negative) and SK-BR-3 (ER negative; PR negative; HER2 positive) cells. The Akt inhibition affected glycolysis and markedly decreased levels of HK2, pyruvate kinase M2, ATP and lactate.

Wang et al (60) synthesized a series of UA diamine derivatives to evaluate their biological activities. The authors demonstrated that the carbon chains of the modified UA derivatives competed strongly with glucose for binding sites in glucokinase (GK). Furthermore, the combination of 2-deoxy-D-glucose (2-DG) and UA derivative US597 (UA-4) induced cell cycle arrest at the G2/mitotic (M) phase, promoted caspase-dependent cell death, reduced HK activity, aggravated depletion of intracellular ATP, decreased lactate production and synergistically inhibited cancer cell growth in vitro (HepG2) and in vivo (H22). Another study indicated that the UA derivative UP12 could bind to the active sites of GK, GLUT1 and ATPase in hepatocellular carcinoma (61). Combined with 2-DG, UP12 depleted intracellular ATP, decreased lactate production and arrested an increased number of cancer cells at the synthesis and G2/M cell cycle phases (61).

\section{Anticancer effect of ursolic acid via reduction of mitochondrial oxidative stress}

In addition to energy production, mitochondria are involved in the regulation of a number of processes including the generation of reactive oxygen species (ROS), redox molecules and metabolites (7). The majority of these by-products are removed by free radical scavenger molecules, including superoxide dismutase (SOD), in order to maintain balance under normal physiological conditions and counteract initiation of cell death (62). Oxidative stress is induced when the functional domain of mitochondria is exposed to high concentrations of ROS (63). Mild oxidative stress often has protective effects including promoting cell survival, proliferation and differentiation. However, severe oxidative stress causes irreversible damage, decreases proliferation, and induces aging, apoptosis and necrosis (64). In cancer cells, mitochondrial ROS amplify the tumorigenic phenotype and accelerate the accumulation of additional mutations that lead to metastatic behavior (65). Targeting of mitochondrial metabolism that contributes to redox regulation presents a promising avenue for future anticancer therapy $(66,67)$.

Synthesized UA derivatives 5, 17 and 23 inhibited cell growth in the human bladder cancer cell line NTUB1 (68). Derivative 17 significantly increased the production of ROS for $24 \mathrm{~h}$, while 5 and 23 did so for $48 \mathrm{~h}$. Wu et al (32) evaluated ROS generation in osteosarcoma U-2 and MG-63 cells exposed to a combination of UA and zoledronic acid (ZOL) using the fluorescent dye hydroethidine. The results indicated that the UA/ZOL combination increased intracellular ROS levels more effectively than either of the compounds alone. Furthermore, N-acetyl-L-cysteine, a ROS scavenger, suppressed this effect, and significantly reduced the apoptosis induced by the UA/ZOL combination. Mitochondrial oxidative damage is further aggravated by accumulation of high ROS level. A high level of ROS inhibited the activity of respiratory enzymes and electron transport through the respiratory chain (67). ROS adversely impacted oxidase and antioxidant enzyme activity, stimulated depolarization of mitochondrial membrane potential and facilitated1-methyl-4phenyl-1,2,3,6-tetrahydropyridine pore opening (66). These actions increased mitochondrial membrane permeability and resulted in changes in calcium metabolism, leading to mitochondrial morphological destruction, loss of mitochondrial function and cell death (66).

In the human breast cancer cell line MDA-MB-231, UA decreased the mitochondrial $\Delta \Psi \mathrm{m}$, demonstrated by affecting the level of 5,5',6,6'-tetrachloro-1,1',3,3'-tetraethylbenzimi-dazolyl- 


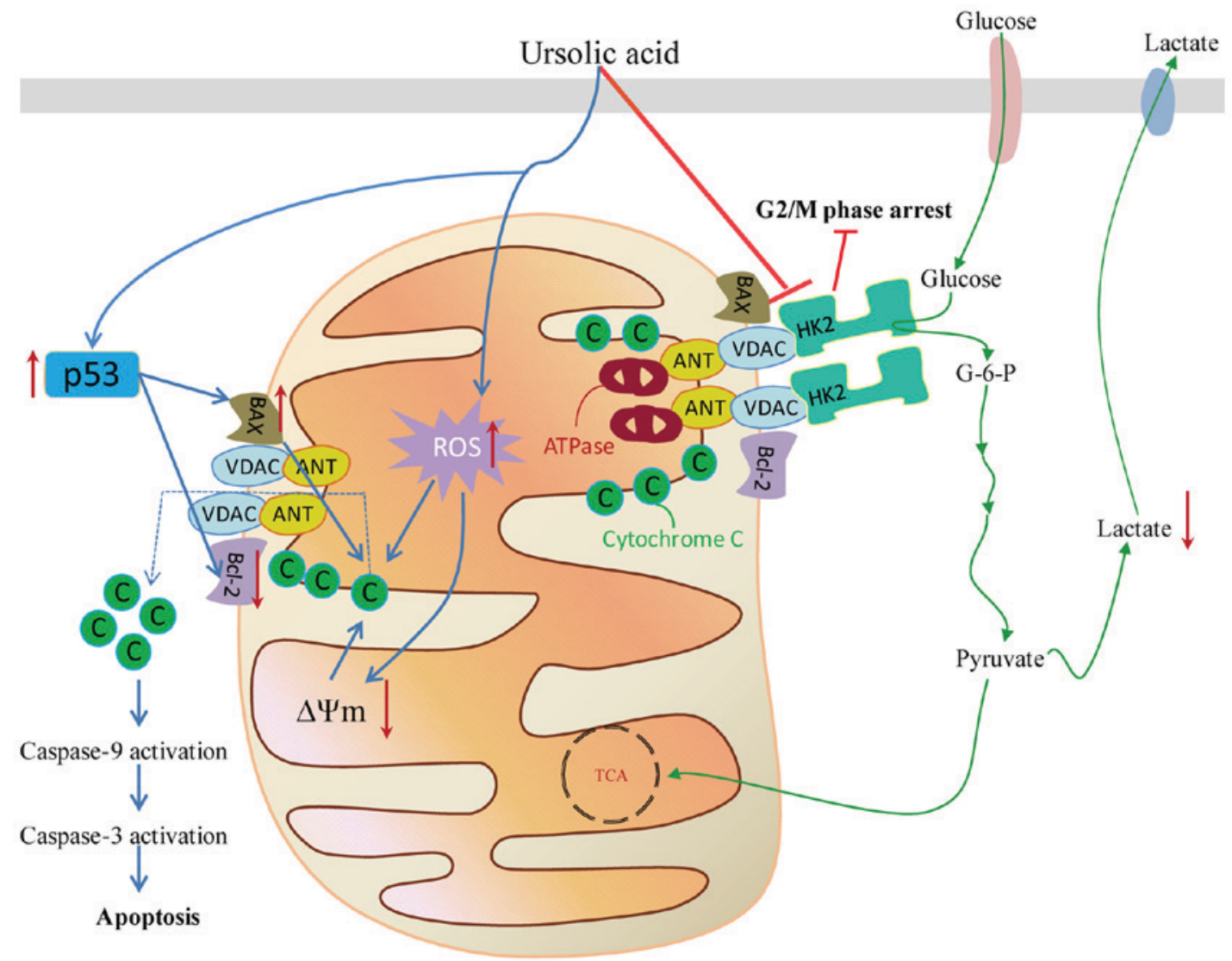

Figure 2. Schematic presentation of the antiproliferative effect of the UA targeting the mitochondrial pathway in cancer cells, including the associated metabolic enzymes, the promotion of ROS production and accumulation in mitochondria under stress conditions, destabilization of mitochondrial membrane potential and activation of the 553 pathway to decrease proliferation or promote apoptosis. G2, gap 2; M, mitosis; G-6-P, glucose 6-phosphate; HK2, hexokinase 2; Bcl-2, B-cell lymphoma 2; VDAC, voltage dependent anion channel; ANT, adenine nucleus translocator; ATP, adenosine triphosphate; ROS, reactive oxygen species; C, cytochrome C; TCA, tricarboxylic acid; $\Delta \Psi \mathrm{m}$, membrane potential.

carbocyanine iodide (JC-1) which gathered in the mitochondrial matrix to form aggregates (69). Another study also revealed that after $24 \mathrm{~h}$ of treatment with $15 \mu \mathrm{M}$ of $\mathrm{UA}$, human melanoma M4Beu cells had a low mitochondrial membrane potential, identified by staining with JC-1/TOTO-3 iodide. Therefore, UA may participate in ROS-mediated oxidative stress, activate metabolic disturbances in mitochondria in cancer cells and induce proapoptotic cascade reactions (55). The detailed mechanisms of the anticancer effects of UA require further research.

\section{Anticancer effect of ursolic acid mediated by the p53-modulated mitochondrial pathway}

Inactivation of tumor suppressor genes is an important initiating factor for tumor reprogramming. One of the established tumor suppressors, $\mathrm{p} 53$ protein, encoded by human tumor protein $\mathrm{p} 53$ (TP53) gene, controls tumorigenesis through various cellular mechanisms including DNA damage repair, cell cycle regulation and cell death (70). According to the Cancer Gene Census mutation database, TP53 is the most frequently mutated gene (36.1\%) in different types of cancer (71). p53 serves an important role in modulating the balance between mitochondrial respiration and glycolysis (70). Matoba et al (72) reported that p53 regulated the expression of the synthesis of cytochrome $\mathrm{C}$ oxidase 2 ( $\mathrm{SCO} 2$ ) protein, which is required for regulating the cytochrome $\mathrm{C}$ oxidase complex. The authors revealed that oxygen consumption was reduced in the liver mitochondria of p53 $3^{-/-}$knockout mice, as well as in p53 $3^{-/}$HCT116 deficient cells compared with the wild type. In addition, lactate production was increased in $\mathrm{p} 53^{-/}$knockout cells. Further study verified that SCO2links p53 to mitochondrial respiration, providing a possible explanation for the Warburg effect (73). In addition to regulating $\mathrm{SCO} 2$ transactivation and expression, $\mathrm{p} 53$ regulates mitochondrial biogenesis genes, including mitochondrial transcription factor A and apoptosis-inducing factor which encode for major apoptosis-affecting proteins involved in complex 1 assembly (72). p53 regulates expression of ferredoxin reductase protein responsible for the maturation of iron-sulfur proteins essential in electron transfer reactions. p53 also modulates fatty acid metabolism through sphingosine kinase 1 and lipin 1, which can promote cell growth and mediate nutritional and genotoxic stress signals (74).

p53 may induce growth arrest or programmed cell death through transcriptional activity. Nam and Kim (75) reported that treatment with UA in human colon adenocarcinoma SW480 cells significantly increased the expression level and transcriptional activity of $\mathrm{p} 53$, as well as that of $\mathrm{NF}-\kappa \beta$ and Bax. UA also enhanced p21 transcriptional activity and induced caspase3-dependent apoptosis (76). Manu and Kuttan (77) suggested that the activation of p53 by treatment with UA mediated activation of proapoptotic pathways in B16F-10 melanoma cells. Yu et al (78) demonstrated that treatment with UA induced 
cycle arrest and apoptosis in the human hepatoma cell line SMMC-7721. The authors also verified that the proapoptotic and regulatory proteins p53 and Bax were upregulated while the antiapoptotic protein $\mathrm{Bcl}-2$ was downregulated following treatment with UA. Furthermore, the mRNA level of growth differentiation factor 15, SOD2 and activating transcription factor 3 were increased, while Fos levels were decreased. The p53 inhibitor pifithrin- $\alpha$ blocked these effects, supporting the role of $\mathrm{p} 53$. The aforementioned studies provide a preliminary interpretation of UA signaling via activation of the p53 pathway and the induction of tumor cell apoptosis. However, p53 can regulate the expression of a variety of metabolism-associated enzymes in mitochondria and, thus, its role may not be limited to the induction of apoptosis (78). The metabolic mechanism of the anticancer effect of UA via the p53 pathway requires further investigation.

\section{Conclusions and perspectives}

Reprogrammed energy metabolism is an emerging hallmark of cancer phenotyping. In the search for new anticancer agents, phytochemicals have drawn an increasing amount of attention. Clinicians are searching for natural drugs with a high efficiency, which are less toxic to normal cells compared with conventional treatments. Mitochondrial metabolism was investigated as a target for cancer therapy, owing to the reemergence of mitochondria as central metabolic organelles adversely affected by tumorigenesis. Numerous studies suggest that UA regulates mitochondrial function through the activation of multiple pathways. UA regulates the expression of associated metabolic enzymes, decreases tumor proliferation, promotes ROS production and accumulation in mitochondria under stress conditions, destabilizes mitochondrial membrane potential, activates the p53 pathway and promotes apoptosis in various types of cancer cells (Fig. 2). Further research investigating the cellular and molecular mechanisms underlying the effects of $\mathrm{UA}$ is required for the development of new therapeutic agents.

\section{Acknowledgements}

Not applicable.

\section{Funding}

The present study was supported by the National Natural Science Foundation of China (grant no. 81660468).

\section{Availability of data and materials}

Not applicable.

\section{Authors' contributions}

XMF conducted the literature review and wrote the manuscript. XLS was involved in drafting and revising the manuscript. Both authors read and approved the final manuscript.

\section{Ethics approval and consent to participate}

Not applicable.

\section{Patient consent for publication}

Not applicable.

\section{Competing interests}

The authors declare that they have no competing interests.

\section{References}

1. Warburg $\mathrm{O}$, Wind $\mathrm{F}$ and Negelein $\mathrm{E}$ : The metabolism of tumors in the body. J Gen Physiol 8: 519-530, 1927.

2. Warburg O: On the origin of cancer cells. Science 123: 309-314, 1956.

3. Vander Heiden MG, Cantley LC and Thompson CB: Understanding the Warburg effect: The metabolic requirements of cell proliferation. Science 324: 1029-1033, 2009.

4. Gatenby RA and Gillies RJ: Why do cancers have high aerobic glycolysis? Nat Rev Cancer 4: 891-899, 2004

5. Vlassenko AG, McConathy J, Couture LE, Su Y, Massoumzadeh P, Leeds HS, Chicoine MR, Tran DD, Huang J, Dahiya S, et al: Aerobic glycolysis as a marker of tumor aggressiveness: Preliminary data in high grade human brain tumors. Dis Markers 2015: 874904, 2015.

6. Lunt SY and Vander Heiden MG: Aerobic glycolysis: Meeting the metabolic requirements of cell proliferation. Annu Rev Cell Dev Biol 27: 441-464, 2011.

7. Alberts B: Molecular biology of the cell (4th edition). New York, Garland Science, 2002.

8. Mathupala SP, Ko YH and Pedersen PL: The pivotal roles of mitochondria in cancer: Warburg and beyond and encouraging prospects for effective therapies. Biochim Biophys Acta 1797: 1225-1230, 2010

9. Wajant H: The Fas signaling pathway: More than a paradigm. Science 296: 1635-1636, 2002.

10. Desagher S and Martinou JC: Mitochondria as the central control point of apoptosis. Trends Cell Biol 10: 369-377, 2000.

11. Luo X, Budihardjo I, Zou H, Slaughter C and Wang X: Bid, a $\mathrm{Bcl} 2$ interacting protein, mediates cytochrome $\mathrm{c}$ release from mitochondria in response to activation of cell surface death receptors. Cell 94: 481-490, 1998.

12. Jiang $X$ and Wang X: Cytochrome C-mediated apoptosis. Annu Rev Biochem 73: 87-106, 2004.

13. Ernster L and Schatz G: Mitochondria: A historical review. J Cell Biol 91: 227s-255s, 1981.

14. Hill RA and Connolly JD: Triterpenoids. Nat Prod Rep 30: 1028-1065, 2013

15. Jager S, Trojan H, Kopp T, Laszczyk MN and Scheffler A: Pentacyclic triterpene distribution in various plants-rich sources for a new group of multi-potent plant extracts. Molecules 14: 2016-2031, 2009

16. Szakiel A, Paczkowski C, Pensec F and Bertsch C: Fruit cuticular waxes as a source of biologically active triterpenoids. Phytochem Rev 11: 263-284, 2012.

17. Wozniak L, Skapska S and Marszalek K: Ursolic Acid-A pentacyclic triterpenoid with a wide spectrum of pharmacological activities. Molecules 20: 20614-20641, 2015.

18. Kashyap D, Tuli HS and Sharma AK: Ursolic acid (UA): A metabolite with promising therapeutic potential. Life Sci 146: 201-213, 2016.

19. Santos Rosa C, Garcia Gimenez MD, Saenz Rodriguez MT and De la Puerta Vazquez R: Antihistaminic and antieicosanoid effects of oleanolic and ursolic acid fraction from Helichrysum picardii. Pharmazie 62: 459-462, 2007.

20. Xu T, Wang X, Zhong B, Nurieva RI, Ding S and Dong C: Ursolic acid suppresses interleukin-17 (IL-17) production by selectively antagonizing the function of RORgamma t protein. J Biol Chem 286: 22707-22710, 2011.

21. Wei ZY, Chi KQ, Wang KS, Wu J, Liu LP and Piao HR: Design, synthesis, evaluation, and molecular docking of ursolic acid derivatives containing a nitrogen heterocycle as anti-inflammatory agents. Bioorg Med Chem Lett 28: 1797-1803, 2018.

22. Lee J, Lee HI, Seo KI, Cho HW, Kim MJ, Park EM and Lee MK: Effects of ursolic acid on glucose metabolism, the polyol pathway and dyslipidemia in non-obese type 2 diabetic mice. Indian J Exp Biol 52: 683-691, 2014. 
23. Poongunran J, Perera HK, Jayasinghe L, Fernando IT, Sivakanesan R, Araya H and Fujimoto Y: Bioassay-guided fractionation and identification of $\alpha$-amylase inhibitors from Syzygium cumini leaves. Pharm Biol 55: 206-211, 2017.

24. Lee J, Yee ST, Kim JJ, Choi MS, Kwon EY, Seo KI and Lee MK: Ursolic acid ameliorates thymic atrophy and hyperglycemia in streptozotocin-nicotinamide-induced diabetic mice. Chem Biol Interact 188: 635-642, 2010.

25. Kazmi I, Rahman M, Afzal M, Gupta G, Saleem S, Afzal O, Shaharyar MA, Nautiyal U, Ahmed S and Anwar F: Anti-diabetic potential of ursolic acid stearoyl glucoside: A new triterpenic gycosidic ester from Lantana camara. Fitoterapia 83: 142-146, 2012.

26. Wang YL, Wang ZJ, Shen HL, Yin M and Tang KX: Effects of artesunate and ursolic acid on hyperlipidemia and its complications in rabbit. Eur J Pharm Sci 50: 366-371, 2013.

27. Sundaresan A, Radhiga T and Pugalendi KV: Effect of ursolic acid and Rosiglitazone combination on hepatic lipid accumulation in high fat diet-fed C57BL/6J mice. Eur J Pharmacol 741: 297-303, 2014.

28. Seo DY, Lee SR, Heo JW, No MH, Rhee BD, Ko KS, Kwak HB and Han J: Ursolic acid in health and disease. Korean J Physiol Pharmacol 22: 235-248, 2018.

29. Kunkel SD, Elmore CJ, Bongers KS, Ebert SM, Fox DK, Dyle MC, Bullard SA and Adams CM: Ursolic acid increases skeletal muscle and brown fat and decreases diet-induced obesity, glucose intolerance and fatty liver disease. PLoS One 7: e39332, 2012.

30. Ma JQ, Ding J, Zhang L and Liu CM: Protective effects of ursolic acid in an experimental model of liver fibrosis through Nrf2/ARE pathway. Clin Res Hepatol Gastroenterol 39: 188-197, 2015.

31. Hollosy F, Idei M, Csorba G, Szabó E, Bökönyi G, Seprödi A, Mészáros G,Szende B and Kéri G: Activation of caspase-3 protease during the process of ursolic acid and its derivative-induced apoptosis. Anticancer Res 21: 3485-3491, 2001.

32. Wu CC, Huang YF, Hsieh CP, Chueh PJ and Chen YL: Combined use of zoledronic acid augments ursolic Acid-induced apoptosis in human osteosarcoma cells through enhanced oxidative stress and autophagy. Molecules 21: pii: E1640, 2016

33. Jiang K, Chi T, Li T, Zheng G, Fan L, Liu Y, Chen X, Chen S, Jia L and Shao JW: Correction: A smart pH-responsive nano-carrier as a drug delivery system for the targeted delivery of ursolic acid: Suppresses cancer growth and metastasis by modulating P53/MMP-9/PTEN/CD44 mediated multiple signaling pathways. Nanoscale 10: 6212-6213, 2018.

34. Zhang H, Li X, Ding J, Xu H, Dai X, Hou Z, Zhang K, Sun K and Sun W: Delivery of ursolic acid (UA) in polymeric nanoparticles effectively promotes the apoptosis of gastric cancer cells through enhanced inhibition of cyclooxygenase 2 (COX-2). Int J Pharm 441: 261-268, 2013.

35. Harmand PO, Duval R, Liagre B, Jayat-Vignoles C, Beneytout JL, Delage $C$ and Simon A: Ursolic acid induces apoptosis through caspase-3 activation and cell cycle arrest in HaCat cells. Int J Oncol 23: 105-112, 2003

36. Cha HJ, Park MT, Chung HY, Kim ND, Sato H, Seiki M and Kim KW: Ursolic acid-induced down-regulation of MMP-9 gene is mediated through the nuclear translocation of glucocorticoid receptor in HT1080 human fibrosarcoma cells. Oncogene 16 : 771-778, 1998

37. Luo J, Hu YL and Wang H: Ursolic acid inhibits breast cancer growth by inhibiting proliferation, inducing autophagy, and apoptosis and suppressing inflammatory responses via the $\mathrm{PI} 3 \mathrm{~K} / \mathrm{AKT}$ and NF- $\mathrm{B}$ signaling pathways in vitro. Exp Ther Med 14: 3623-3631, 2017

38. Lewinska A, Adamczyk-Grochala J,Kwasniewicz E, Deregowska A and Wnuk M: Ursolic acid-mediated changes in glycolytic pathway promote cytotoxic autophagy and apoptosis in phenotypically different breast cancer cells. Apoptosis 22: 800-815, 2017.

39. Yeh $\mathrm{CT}, \mathrm{Wu} \mathrm{CH}$ and Yen GC: Ursolic acid, a naturally occurring triterpenoid, suppresses migration and invasion of human breast cancer cells by modulating c-Jun N-terminal kinase, Akt and mammalian target of rapamycin signaling. Mol Nutr Food Res 54: 1285-1295, 2010

40. Subbaramaiah K, Michaluart P, Sporn MB and Dannenberg AJ: Ursolic acid inhibits cyclooxygenase-2 transcription in human mammary epithelial cells. Cancer Res 60: 2399-2404, 2000.

41. Liu L, Zhang J, Li M, Zhang X, Li Z, Wang L, Wu J and Luo C: Inhibition of HepG2 cell proliferation by ursolic acid and polysaccharides via the downregulation of cyclooxygenase-2. Mol Med Rep 9: 2505-2511,2014
42. Tian Z, Lin G, Zheng RX, Huang F, Yang MS and Xiao PG: Anti-hepatoma activity and mechanism of ursolic acid and its derivatives isolated from Aralia decaisneana. World J Gastroenterol 12: 874-879, 2006.

43. Limami Y, Pinon A, Leger DY, Pinault E, Delage C, Beneytout JL, Simon A and Liagre B: The P2Y2/Src/p38/COX-2 pathway is involved in the resistance to ursolic acid-induced apoptosis in colorectal and prostate cancer cells. Biochimie 94: 1754-1763, 2012

44. Huang HC, Huang CY, Lin-Shiau SY and Lin JK: Ursolic acid inhibits IL-1beta or TNF-alpha-induced C6 glioma invasion through suppressing the association ZIP/p62 with PKC-zeta and downregulating the MMP-9 expression. Mol Carcinog 48: 517-531, 2009.

45. Wang X, Zhang F, Yang L, Mei Y, Long H, Zhang X, Zhang J, Qimuge $S$ and Su X: Ursolic acid inhibits proliferation and induces apoptosis of cancer cells in vitro and in vivo. J Biomed Biotechnol 2011: 419343, 2011

46. Li R, Wang X, Zhang XH, Chen $\mathrm{HH}$ and Liu YD: Ursolic acid promotes apoptosis of SGC-7901 gastric cancer cells through ROCK/PTEN mediated mitochondrial translocation of cofilin-1. Asian Pac J Cancer Prev 15: 9593-9597, 2014.

47. Tang Q, Ji Q, Tang Y, Chen T, Pan G, Hu S, Bao Y, Peng W and Yin P: Mitochondrial translocation of cofilin-1 promotes apoptosis of gastric cancer BGC-823 cells induced by ursolic acid. Tumour Biol 35: 2451-2459, 2014.

48. Tang C, Lu YH, Xie JH, Wang F, Zou JN, Yang JS, Xing YY and Xi T: Downregulation of survivin and activation of caspase-3 through the PI3K/Akt pathway in ursolic acid-induced HepG2 cell apoptosis. Anticancer Drugs 20: 249-258, 2009.

49. Wallace DC: A mitochondrial paradigm of metabolic and degenerative diseases, aging, and cancer: A dawn for evolutionary medicine. Annu Rev Genet 39: 359-407, 2005.

50. Cheng TL, Liao CC, Tsai WH, Lin CC, Yeh CW, Teng CF and Chang WT: Identification and characterization of the mitochondrial targeting sequence and mechanism in human citrate synthase. J Cell Biochem 107: 1002-1015, 2009.

51. Wilson JE: Isozymes of mammalian hexokinase: Structure, subcellular localization and metabolic function. J Exp Biol 206: 2049-2057, 2003

52. Pedersen PL, Mathupala S, Rempel A, Geschwind JF and Ko YH: Mitochondrial bound type II hexokinase: A key player in the growth and survival of many cancers and an ideal prospect for therapeutic intervention. Biochim Biophys Acta 1555: 14-20, 2002.

53. Mathupala SP, Ko YH and Pedersen PL: Hexokinase-2 bound to mitochondria: Cancer's stygian link to the 'Warburg Effect' and a pivotal target for effective therapy. Semin Cancer Biol 19: 17-24, 2009.

54. Shoshan-Barmatz V, Zakar M, Rosenthal K and Abu-Hamad S: Key regions of VDAC1 functioning in apoptosis induction and regulation by hexokinase. Biochim Biophys Acta 1787: 421-430, 2009.

55. Duval RE, Harmand PO, Jayat-Vignoles C, Cook-Moreau J, Pinon A, Delage C and Simon A: Differential involvement of mitochondria during ursolic acid-induced apoptotic process in HaCaT and M4Beu cells. Oncol Rep 19: 145-149, 2008.

56. Shanmugam MK, Dai X, Kumar AP, Tan BK, Sethi G and Bishayee A: Ursolic acid in cancer prevention and treatment: Molecular targets, pharmacokinetics and clinical studies. Biochem Pharmacol 85: 1579-1587, 2013.

57. Tang X, Gao J, Chen J, Fang F, Wang Y, Dou H, Xu Q and Qian Z: Inhibition by [corrected] ursolic acid of [corrected] calcium-induced mitochondrial permeability transition and release of two proapoptotic proteins. Biochem Biophys Res Commun 337: 320-324, 2005

58. Shyu MH, Kao TC and Yen GC: Oleanolic acid and ursolic acid induce apoptosis in $\mathrm{HuH} 7$ human hepatocellular carcinoma cells through a mitochondrial-dependent pathway and downregulation of XIAP. J Agric Food Chem 58: 6110-6118, 2010.

59. Saraswati S, Agrawal SS and Alhaider AA: Ursolic acid inhibits tumor angiogenesis and induces apoptosis through mitochondrial-dependent pathway in Ehrlich ascites carcinoma tumor. Chem Biol Interact 206: 153-165, 2013.

60. Wang J, Jiang Z, Xiang L, Li Y, Ou M, Yang X, Shao J, Lu Y, Lin L, Chen J, et al: Synergism of ursolic acid derivative US597 with 2-deoxy-D-glucose to preferentially induce tumor cell death by dual-targeting of apoptosis and glycolysis. Sci Rep 4: 5006, 2014.

61. Dong H, Yang X, Xie J, Xiang L, Li Y, Ou M, Chi T, Liu Z, Yu S Gao Y, et al: UP12, a novel ursolic acid derivative with potential for targeting multiple signaling pathways in hepatocellular carcinoma. Biochem Pharmacol 93: 151-162, 2015. 
62. Wang Y, Branicky R, Noe A and Hekimi S: Superoxide dismutases: Dual roles in controlling ROS damage and regulating ROS signaling. J Cell Biol 217: 1915-1928, 2018.

63. Zorov DB, Juhaszova M and Sollott SJ: Mitochondrial reactive oxygen species (ROS) and ROS-induced ROS release. Physiol Rev 94: 909-950, 2014

64. Sies H: Oxidative stress: A concept in redox biology and medicine. Redox Biol 4: 180-183, 2015.

65. Moloney JN and Cotter TG: ROS signalling in the biology of cancer. Semin Cell Dev Biol 80: 50-64, 2018.

66. Sabharwal SS and Schumacker PT: Mitochondrial ROS in cancer: Initiators, amplifiers or an Achilles' heel? Nat Rev Cancer 14: 709-721, 2014.

67. Shadel GS and Horvath TL: Mitochondrial ROS signaling in organismal homeostasis. Cell 163: 560-569, 2015.

68. Tu HY, Huang AM, Wei BL, Gan KH, Hour TC, Yang SC, Pu YS and Lin CN: Ursolic acid derivatives induce cell cycle arrest and apoptosis in NTUB1 cells associated with reactive oxygen species. Bioorg Med Chem 17: 7265-7274, 2009.

69. Kim KH, Seo HS, Choi HS, Choi I, Shin YC and Ko SG: Induction of apoptotic cell death by ursolic acid through mitochondrial death pathway and extrinsic death receptor pathway in MDA-MB-231 cells. Arch Pharm Res 34: 1363-1372, 2011.

70. Ventura A, Kirsch DG, McLaughlin ME, Tuveson DA, Grimm J, Lintault L, Newman J, Reczek EE, Weissleder R and Jacks T: Restoration of 553 function leads to tumour regression in vivo. Nature 445: 661-665, 2007.
71. Hollstein M, Sidransky D, Vogelstein B and Harris CC: p53 mutations in human cancers. Science 253: 49-53, 1991.

72. Matoba S, Kang JG, Patino WD, Wragg A, Boehm M, Gavrilova O, Hurley PJ, Bunz F and Hwang PM: p53 regulates mitochondrial respiration. Science 312: 1650-1653, 2006.

73. Kruse JP and Gu W: p53 aerobics: The major tumor suppressor fuels your workout. Cell Metab 4: 1-3, 2006.

74. Heffernan-Stroud LA, Helke KL, Jenkins RW, De Costa AM, Hannun YA and Obeid LM: Defining a role for sphingosine kinase 1 in p53-dependent tumors. Oncogene 31: 1166-1175, 2012.

75. Nam H and Kim MM: Ursolic acid induces apoptosis of SW480 cells via p53 activation. Food Chem Toxicol 62: 579-583, 2013.

76. Zhang X, Song X, Yin S, Zhao C, Fan L and Hu H: p21 induction plays a dual role in anti-cancer activity of ursolic acid. Exp Biol Med (Maywood) 241: 501-508, 2016.

77. Manu KA and Kuttan G: Ursolic acid induces apoptosis by activating p53 and caspase-3 gene expressions and suppressing NF-kappaB mediated activation of bcl-2 in B16F-10 melanoma cells. Int Immunopharmacol 8: 974-981, 2008.

78. Yu YX, Gu ZL, Yin JL, Chou WH, Kwok CY, Qin ZH and Liang ZQ: Ursolic acid induces human hepatoma cell line SMMC-7721 apoptosis via p53-dependent pathway. Chin Med J (Engl) 123: 1915-1923, 2010. 